\title{
A falta da falta e o objeto da angústia
}

\author{
The lack of lack and the object of anguish
}

\author{
Maria Angélica Augusto de Mello PISETTA'
}

\begin{abstract}
Resumo
Pretende-se, com este artigo, discutir a especificidade do objeto da angústia, declarado como inexistente por Freud. Com a formulação teórica estabelecida por Lacan em 1962/1963 de um objeto conceitual que escapa a toda significação e apreensão imaginária, essa discussão tomou novos contornos. Trata-se do conceito de objeto a, um objeto constituído de pura falta, decorrente de uma insatisfação. Este texto desenvolveu-se a partir da concepção da perda do objeto de satisfação, citada por Freud como mítica. Intenta-se também aproximar o conceito de objeto a dos conceitos de "estranho" e "familiar", relacionados por Freud em 1919 ao conceito da angústia, considerando-se a declaração lacaniana da proximidade do que é familiar na vivência deste conceito.
\end{abstract}

Unitermos: Ansiedade. Freud. Psicanálise.

\begin{abstract}
In this paper we intend to discuss the specific nature of the object of anguish, stated by Freud as something that does not exist. With the theoretical formulation established by Lacan (in 1962-1963), of a conceptual object that escapes every significance and imaginary apprehension, this discussion has adopted new outlines. It is all about the concept of "object a", an object composed of pure lack, arising from dissatisfaction. We will start with the idea of the loss of the object of satisfaction, quoted by Freud as a myth. We also intend to approximate the concept of the" object a" of the concepts of "strange" and "familiar", espoused by Freud in 1919, to the concept of anguish, prompted by Lacan's statement about the proximity of what is familiar in the anguish experience.
\end{abstract}

Uniterms: Anxiety. Freud. Psychoanalysis.

A angústia tem inegável relação com a expectativa: é angústia por algo. Tem uma qualidade de indefinição e falta de objeto (Freud, 1926/1976, p.189, grifo nosso).

Esseobjeto a, é sempre dele que se trata quando Freud fala de objeto a propósito da angústia (Lacan, 1962/2005, p.50).

A angústia apresenta-se como um imperativo na clínica e convoca à análise. Não apenas sua definição como, acima de tudo, seu manejo, apresentam-se a partir de impasses que demandam sempre análise e aprofundamento. Lacan (1962/2005, p.13) não deixa de sublinhar que retomar o estatuto privilegiado da angústia junto aos conceitos da psicanálise demarca que os analistas são colocados à prova a todo momento na identificação do quanto de angústia os pacientes podem suportar. Para articular essas questões; pretende-se discutir os conceitos de angústia e objeto $a$, a partir da interlocução com os textos de Freud sobre o conceito de angústia.

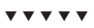

1 Universidade Católica de Petrópolis, Faculdade de Psicologia. R. Br do Amazonas, 124, Centro, 25645-045, Petrópolis, RJ, Brasil. E-mail: <angelica.pisetta@ucp.br>. 
Desta maneira, acredita-se ser possível avançar na discussão do que causa angústia.

Existe uma alteração importante na teorização da angústia em Freud. Na primeira teoria (compreendida até 1926), com as proposições de Inibições, sintomas e ansiedade), a angústia é considerada um destino do afeto que fora desligado da ideia pela incidência do recalque (Freud, 1926/1976). Portanto, a angústia nesta concepção é posterior ao recalque. A partir da retomada da análise do caso clínico da fobia de Hans, em 1926, Freud acentuou proposições básicas que redimensionaram o estatuto da angústia.

Em primeiro lugar, ressalta-se a noção do perigo de castração que incide "de fora" do aparelho psíquico (diretamente do agente repressor, o pai), compreendido então como um "perigo real". Contudo, a indicação de um real no perigo de que se trata o da castração não remete logicamente a um evento objetivo qualquer, mas à própria pulsão, que é tomada como se atuasse "de fora" para que alguma forma de defesa pudesse se constituir. Assim, o interno-externo que a pulsão denota surge na teorização da angústia como indicativo de uma equivalência entre a pulsão e a castração, demarcando uma estratégia neurótica inicial no confronto com o perigo traumático.

A indicação freudiana do "real" no perigo da castração remete diretamente a um trauma psíquico. Freud (1926/1976, p.145) destaca que não se pode inferir a existência do princípio do prazer atuante neste momento traumático, já que não há preparação alguma para tal. Nesse sentido, a postulação do conceito de recalcamento primário dá conta deste momento mítico de causação do sujeito, já que é por este (o recalque primário) que haverá uma primeira apropriação do sujeito em relação ao trauma.

Com a pressuposição do momento traumático como fundamento do primeiro recalque, a sustentação da angústia como secundária em relação a ele perde sentido, e ela é então pensada como a alavanca afetiva que promove a inscrição do primeiro recalque. Nesse sentido, ela é defesa contra o traumático.

A angústia seria, neste ponto de vista, anterior à própria regulação dada pelo princípio do prazer, que se instauraria por meio do recalque. Em Além do princípio do prazer, Freud (1920/1976, p.60), Freud antecipa um pouco essa concepção, quando se pergunta que relações haveria entre a compulsão à repetição (principal motor da construção do conceito de pulsão de morte), tão evidente na clínica, e o princípio do prazer, sobre o qual repousava, até então, sua teorização. Em virtude do caráter conservador da pulsão, ele admite momentos míticos em que o princípio do prazer nem sequer estaria em jogo. Nesse sentido, a angústia encontra sua inscrição antes do recalque originário.

A angústia enquanto "mecanismo" situa-se antes do princípio do prazer. Produzi-la, como proteção ao encontro com o traumático, é o objetivo dos sonhos traumáticos. Desta forma, diz Freud, na neurose traumática os sonhos reproduzem uma situação de extremo sofrimento e repetição do trauma, e não podem estar, portanto, referidos ao princípio do prazer. Tal repetição poderia ser assim pensada como uma tentativa de estabelecê-lo por meio do desenvolvimento da angústia, porque não houve possibilidade de sua atuação como sinal no momento da vivência traumática. Indicam assim, via de regra, uma tentativa de estabelecimento do prazer, o que indica que ele o princípio do prazer não estaria estabelecido a priori.

Não se pode mais considerar, então, que é a libido não utilizada que causa a angústia, mas, em função da teoria do trauma, Freud indica duas origens da angústia: uma consequente do momento traumático e outra como sinal que ameaça com uma repetição de um determinado momento. Aqui transparece a necessidade lógica de a instância egoica ser considerada a produtora e a sede real da angústia.

O conceito de recalque primário é fundamental na análise da angústia. Freud mesmo o considera um dos conceitos imprescindíveis de sua teorização. A concepção de 1926, que fala da anterioridade da angústia em relação ao recalque, coloca este pressuposto em xeque. Se a divisão psíquica é inaugurada pelo recalque primário (e, nesse sentido, todos os objetos também o são), como conceber um objeto anterior a ele? Freud o faz indiretamente com a angústia, quando indica que algo a causa. O conceito de objeto sofre uma variação a partir desta remodelação, colocando à mostra um impasse metapsicológico. De que objeto suscitador da experiência angustiante se pode falar neste momento considerado por Freud como anterior ao recalque? Se há um objeto que representa perigo para o psiquismo, 
e que, portanto, desencadearia a reação de angústia, como pode ser este objeto compreendido em relação ao psiquismo, se não for visto como uma consequência do recalque? Essas questões estão abordadas na delimitação do objeto da angústia.

Freud avança na discussão da questão da angústia, que toma toda sua obra, delimitando que o rochedo da castração instala para todo ser vivente uma falta constitucional sinalizada pela angústia. Nesse sentido, a angústia surge ante a castração e, assim sendo, ela é teorizada como anterior ao recalque, marca da reação inicial ao perigo - que, contudo, não é eliminado, permanecendo atuante no sinal de angústia (Freud, 1926/1976).

Embora a angústia esteja referida à falta de objeto para Freud, ele ressalta que, se há angústia, deve haver algo que se teme (Freud, 1976/1916). O impasse em torno de um objeto para a angústia se mantém, já que o objeto, como conceito, é pensado como posterior ao recalque, mediante o desenvolvimento da libido, que culmina na escolha heterossexual.

Pode-se dizer que há uma contradição em Freud quando ele afirma não haver falta de um objeto para a angústia, já que sua manifestação clínica é tão evidente. A leitura lacaniana da teoria da angústia freudiana apresenta-se, então, como uma ferramenta necessária para se discutir acerca da existência de um objeto que suscite aquilo que é conhecido como angústia.

Nota-se uma intensa modificação na abordagem lacaniana da existência de um objeto para a angústia. A investigação aqui realizada centrou-se nos Seminários 4 (A relação de objeto, Lacan (1956/1995) e 10 A angústia, Lacan (1962/2005). Em 1956, Lacan, destacando a análise da fobia infantil de Hans e concordando com Freud, afirmava a inexistência de tal objeto:

A criança tem medo de que aconteça alguma coisa de real, duas coisas, nos diz ela: que os cavalos mordam, que os cavalos caiam. A fobia não é de modo algum a angústia. A angústia - e aí não faço mais que repetir Freud, que o articulou com perfeição - é algo que é sem objeto. Os cavalos saem da angústia, mas o que eles portam é o medo (Lacan, 1956/1995, p. 252).
Estabelecer os limites entre a fobia e a angústia delimita também a distância entre o objeto da angústia e o objeto fóbico. Lacan considera o primeiro como inexistente, seguindo Freud. Já em 1962 ele trata a questão de forma radicalmente diferente, dedicando a ela um seminário, que serviu como referência principal nesta discussão. Neste seminário, Lacan afirma que considerar a angústia sem objeto é falso. O que ele propõe é uma releitura de sua própria tematização, trazendo para a discussão um novo estatuto para o objeto da angústia.

Não se pretende desenvolver o percurso lacaniano entre essas duas afirmações, somente marcar que neste percurso apresenta-se uma saída teórica para o impasse freudiano da constituição do objeto da angústia(2).

Existe um conceito freudiano que indica uma proximidade entre as teorias freudiana e lacaniana: trata-se do conceito de "estranho"(Unheimlich), ao qual Freud dedicou um artigo em 1919.

\section{O estranho e o familiar:enquadramento da angústia}

O "estranho" é aquela categoria do assustador que remete ao que é conhecido, de velho, e há muito 'familiar (Freud, 1919/1976, p. 277).

É enquadrado que se situa o campo da angústia" (Lacan, 1962/2005, p. 86).

O fenômeno do estranho e suas relações com a angústia destacam-se como pontos nodais do texto freudiano de 1919, O estranho. Analisando o tema do que causa estranheza ao homem, Freud assegura que o antecedente lógico para este fenômeno é o recalque. A análise de neuróticos, bem como a literatura e os contos de fada, produzem material para as articulações deste tema. Após uma incursão linguística pelo termo Unheimlich, Freud afirmou que tudo o que é percebido como "estranho" foi, um dia, extremamente "familiar", destacando uma anterioridade do familiar no fenômeno da angústia.

Circunscrevendo as mais variadas significações para a palavra Unheimlich, em diferentes línguas, Freud

$\boldsymbol{\nabla} \mathbf{\nabla} \boldsymbol{\nabla}$

2 Cabe esclarecer que Lacan também avança no sentido da delimitação do objeto da angústia. Foram abordados seus seminários sobre a relação de objeto (1956/1997) e sobre a angústia (1962/2005), mas um pouco mais tarde, em 1974, Lacan relaciona a angústia ao real, enfatizando que a primeira parte do segundo. 
procurou acentuar a relação do fenômeno do estranho com o processo do recalque. Nesse sentido, Schelling o auxilia: "Unheimlich' é o nome de tudo que deveria ter permanecido ... secreto e oculto mas veio à luz" (Freud, 1919/1976, p.277). O escondido, o oculto, contido no que se manifesta como estranho, caracteriza o recalcado. Outro ponto interessante a destacar aqui é a consideração de que o estranho representa o que deveria ter permanecido oculto. Nesse sentido, o que aí aparece, forçosamente, é o que deveria faltar (Harari, 1997).

$\mathrm{Na}$ perspectiva freudiana do que constitui o recalque, Freud acentua a relação entre o estranho e a castração, destacando que na fase fálica, com a introdução do Édipo, é o pai quem passa a fornecer a interdição à satisfação, marca inaugural da castração. A análise freudiana está centrada na angústia de castração e, pelo Édipo, relacionada ao agente castrador, o pai.

O perigo suscitador de angústia é visto essencialmente como provindo do pai, agente da lei. O perigo de que se trata, tanto no caso Hans (analisado pelo autor), quanto no conto O Homem da Areia, de Hoffmann (utilizado por Freud em 1909 na análise do "estranho") é o perigo da castração, que remete ao perigo real de ser castrado pelo pai. Esta "realidade" é criada porque a criança acredita nela, e introduz a lei à medida que representa a castração simbólica. O que se pretende destacar é o caráter de "estranho", de "perturbador do amor" atribuído ao pai, do qual se espera a castração. É dele que incide a castração que "perturba" o amor incestuoso pela mãe, transformando o que era tão familiar - "os impulsos plenos de desejos edípicos"(Freud, 1909/1976, p.108) - em estranhos desejos inconscientes. Deste modo, Freud sustenta que a angústia aponta para uma falta, versão edípica da castração, repetida nas experiências que causam estranhamento.

Desta forma, promove-se a partir do recalque um efeito de duplicação do eu. Este efeito, do duplo, é analisado por Freud como mais um dos motivos para o surgimento do "estranho". Temos personagens que devem ser considerados idênticos porque parecem semelhantes, iguais ... Essa relação ... é marcada pelo fato de que o sujeito identifica-se com outra pessoa, de tal forma que fica em dúvida sobre quem é o seu eu, ou substitui o seu próprio eu por um estranho. Em outras palavras, há uma duplicação, divisão e intercâmbio do eu (Freud, 1919/1976, p.293).
A substituição do eu no fenômeno do "estranho" proporciona um não reconhecimento. A estratégia da duplicação pode ser percebida, na proposta freudiana, como uma proteção ao eu, uma segurança contra sua destruição (Freud, 1909/1976, p.293), um recuo à castração. Por outro lado, o duplo torna-se um anunciador da morte, na medida em que indica a incompletude própria do sujeito. Como bem assevera Lacan, a duplicação do eu, acompanhada pela angústia, não deixa de marcar a não autonomia do sujeito, já que faz aparecer sua condição de objeto, marcando o lugar da ausência de que o ser humano é feito (Lacan, 1962/2005, p.58). Pela articulação que vai além da angústia de castração, Lacan relaciona a angústia ao real da ausência de significações que constituem o sujeito.

Ainda que orientado pela perspectiva de que a angústia seria fruto do recalque, em $O$ estranho Freud destaca a angústia como primordial, e considera que ela é o afeto ligado à percepção do "estranho", antes mesmo do recalque. Vale lembrar que a angústia aparecia sempre após o recalque, como um destino do afeto primordial ligado a uma ideia que fora recalcada. Assim, raiva, temor e outras emoções transformavam-se em angústia. Isto até 1926, quando então retomou as questões da angústia, no texto Inibições, sintomas e ansiedade. O que se tornou "estranho", pela incidência do recalque, passou a ter a angústia como afeto inicial. Ou, ao menos, perdeu a importância saber se havia outro afeto ligado a tal ideia.

Deve ser indiferente a questão de saber se o que é estranho era, em si, originalmente assustador ou se trazia algum outro afeto ... esse estranho não é nada novo ou alheio, porém algo que é familiar e há muito estabelecido na mente, e que somente se alienou desta através do processo de recalque (Freud, 1919/ 1976, p.298).

Como o recalque é a condição básica para a efetuação da castração, todos os exemplos que Freud oferece como incidências do "estranho" estão ligados a vivências de castração para o sujeito. Freud assevera que o recalque"é condição necessária de um sentimento primitivo que retorna em forma de algo estranho" (Freud, 1919/1976, p.302, grifo nosso).

Se o "estranho" requer o recalque e a angústia Ihe é anterior, não é ele o objeto da angústia, mas encontra-se no cerne deste fenômeno, já que este conta com o reconhecimento de algo que é reconhecido 
como estranho, anteriormente vivido como familiar. O estudo das relações entre o que é familiar e a falta constituinte pode indicar um avanço na circunscrição do objeto da angústia.

\section{(Un)heimlich: estranho/familiar}

A relação do "estranho" com o recalcado é mais marcadamente estabelecida por Freud quando ele destaca a estranheza que o órgão sexual feminino desperta nos neuróticos. O fenômeno demarca a ressignificação fálica que o complexo de castração vem imputar em relação aos demais perigos anteriores a ele. Evidencia-se mais uma vez uma relação entre a castração - como alavanca da entrada e da saída do Édipo - e o efeito de estranhamento, que a falta de pênis na mulher direciona ao recalcamento. Exatamente na questão do reconhecimento da diferença anatômica entre os sexos, a premissa fálica retoma a impossibilidade de reconhecimento da vagina enquanto "outro" sexo, introduzindo, definitivamente, a falta como representação deste vazio.

Acontece com frequência que os neuróticos do sexo masculino declaram que sentem haver algo estranho no órgão genital feminino. Esse lugar Unheimlich, no entanto, é a entrada para o antigo Heim [lar] de todos os seres humanos.... Nesse caso, também, o unheimlich é o que uma vez foi heimisch, "familiar"; o prefixo 'un' ['in-'] é o sinal do recalque (Freud, 1919/1976, p.305).

Freud destaca que se trata de algo "familiar"que retorna como "estranho". Há uma anterioridade lógica do "familiar" em relação ao "estranho", no qual se transforma. O jogo contido no estranho-familiar e no familiar-estranho, que o prefixo Un em alemão anuncia, também serve para pensar esta proximidade entre o interno e o externo. Nesse sentido, há uma não disjunção entre o familiar e o estranho. Pode-se dizer que o familiar para o qual a angústia aponta é um familiar não reconhecido como tal. Deste modo, a experiência que se pode ter a partir do encontro com ele é mais próxima do estranha-mento e da angústia.

O que é Heim, o que é Geheimnis, [segredo, mistério] nunca passou por estes desvios, pelas redes, pelas peneiras do reconhecimento. Manteve-se unheimlich, menos não habituável do que não habitante, menos inabitual do que inabitado (Lacan, 1962/2005, p.87).
Apenas considerando uma não separação linear entre o estranho e o familiar, Lacan define que o que é mais familiar ao sujeito (Heim) manteve-se o mais estranho (Unheimlich), não habitante e inabitado. Essa estrutura pode ser pensada como um vazio radical, que nada habita nem é habitado por qualquer objeto. A aparente dicotomia entre o familiar e o estranho, apresentada por intermédio dos efeitos do recalque, não se sustenta, tendo em vista a proximidade ontológica entre o interno e o externo. A angústia aparece como um sinal de que este lugar vazio pode ter sido obturado. De que objeto se trata, no entanto, na oclusão desta falta primordial?

\section{O objeto $a$ e a falta da falta}

A conceituação do objeto a ocorreu no ano da exposição do seminário de Lacan aqui abordado (1962/63), e representa uma resposta à necessidade lógica da teoria da angústia. A notação $a$, porém, apresenta-se em seus trabalhos desde o princípio, relacionando-se com a definição dos objetos de desejo e identificação. Já o objeto $a$, posterior, é radicalmente diferente. Não se trata de uma vertente imaginária, tampouco simbólica. Sua estrutura remete ao resto da operação significante, àquilo que não é passível de qualquer sentido, resistindo às identificações com o outro. Harari (1997) sustenta, inclusive, que a angústia é o único modo de apropriação subjetiva deste objeto.

Freud considera característica do objeto a condição de sempre ser reencontrado (Freud, 1900/1976, p.235), havendo aí um limite muito próprio ao objeto. 0 limite define-se na própria impossibilidade da superação da perda do objeto de satisfação. É também no movimento interminável em torno deste buraco da não satisfação estrutural que a pulsão se estabelece, havendo aí outra relação a ser estabelecida com o objeto $a$. É o objeto a que vem nesse lugar, para evidenciar que não há resposta para a pressão da pulsão. A essa insistência premente de satisfação responde uma falta radical, produtora do desejo. Nesse sentido, o furo da pulsão é o lugar do objeto a enquanto marca indelével de sua eterna busca. Em função dessa impossibilidade de satisfação, a pulsão será sempre parcial.

O objeto a encontra-se isento de total significação, aliás, de qualquer significação, desde que ele está 
presente em um lugar de falta por excelência, que não encontra sua base nem no imaginário, nem no simbólico. Este conceito refere-se, assim, a uma categoria formal por excelência, não se amoldando a qualquer tentativa descritiva. Por esta característica, nada de empiricamente comprovado refere-se ao objeto $a$. Ele remete ao real, fora da trama significante que institui a cadeia simbólica. No entanto, a rede de significantes é pensada em suas relações com esta estrutura.

A proximidade lógica entre o objeto a e a angústia é demarcada por Lacan quando ele destaca que a angústia sinaliza sua intervenção. Porém, o autor alerta: "isso não equivale a dizer que esse objeto seja apenas o avesso da angústia, mas que ele só intervém, só funciona, em correlação com a angústia" (Lacan, 1962/2005, p.98). Nesse sentido, a experiência subjetiva da angústia aponta para o surgimento do que não deveria surgir, o objeto de pura falta, que ali surge para indicar que este lugar lógico deve permanecer vazio. É, então, da constituição do sujeito que aqui se fala, tanto na angústia quanto em relação ao objeto $a$.

Lacan mostra que a angústia escancara a falta constitutiva do sujeito. Não é ela - como fenômeno - que surge desta falta, já que se apresenta logicamente como indicadora e portadora da verdade desta falta. Seu aparecimento se dá quando a própria falta pode faltar. É importante aqui a referência à linguagem e a consideração de que a falta de que se trata propicia a dubiedade de significações que o discurso promove.

Deste modo, as ligações entre o conceito de angústia e o conceito de sintoma logo se fazem notar. O sintoma se vincula à angústia, quando compreendido como testemunha de que o recalque falhou, e ainda quando compreendido como uma suplência no eu a toda impossibilidade de satisfação (Freud, 1926/1976). Suas relações com a angústia aprofundam-se neste ponto, e por meio delas ele mascara também seu aparecimento, já que ele (o sintoma) vem velar a realidade da angústia. Freud disse na Conferência XXXII que o sintoma e a angústia se representam; contudo, a angústia é anterior ao sintoma e a constituição deste vem como mecanismo egoico para limitar a aparição daquela (Freud, 1933/1976, p.114).

Se o sintoma tenta preencher esta falta primordial, mascarando a verdade da angústia, esta surge para reclamar seu lugar de constituição da verdade no su- jeito - de que há falta. A angústia aponta um mascaramento da verdade, da qual ela é representante. Assim, a angústia não é o indicativo do aparecimento da falta, mas o indicativo de um perigo primordial: de que a falta que constitui o sujeito venha a faltar. É possível vislumbrar isto mais claramente com a frase lacaniana que diz:"Aquilo diante de que o neurótico recua não éa castração, é fazer de sua castração, o que falta ao Outro. É fazer de sua castração algo positivo, ou seja, a garantia da função do Outro (Lacan, 1962/2005, p.56).

A falta promove um apoio ao sujeito, a possibilidade da alteridade, que torna possível a construção de um saber sobre si e sobre o outro. Lacan afirma que quando este apoio falha, obscurecendo os contornos do objeto e do sujeito, surge a angústia. É por causa de uma certa insuficiência que o sujeito se estrutura, na medida em que o outro também porta esta mesma estrutura falha. Assim, o surgimento da angústia está ligado a uma pretensa completude do outro.

O que provoca a angústia é tudo aquilo que nos anuncia, que nos permite entrever que voltaremos ao colo. Não é, ao contrário do que se diz, o ritmo nem a alternância da presença-ausência da mãe. ... A possibilidade da ausência, eis a segurança da presença (Lacan, 1962/2005, p.64).

A angústia aponta para a tentação de que não haja falta no outro. Porém, desta forma, a alteridade não está mais assegurada, e a angústia, com sua certeza que não se deixa reduzir pelos significantes (Harari, 1997, p.49), reclama sua reinstalação.

Retomando Freud, Lacan vai além da castração como último limite do neurótico. Ele recua diante da não separação e da indiferenciação, que tornaria o outro completo, e a angústia é o sinal deste recuo. O neurótico fragiliza-se diante da necessidade de fazer com a sua castração o outro como completo; a partir disso, a alteridade - tanto do outro quanto de si - está aniquilada. Nesse sentido, o resto não especularizável da libido tem a função de garantir a existência para além da imagem autenticada pelo outro. A falta, pois, é a marca desta alteridade, e é quando esta se encontra ameaçada que a angústia dá o alarme.

\section{Referências}

Freud, S. (1976). A interpretação dos sonhos (Vol. 10). Rio de Janeiro: Edição Standard Brasileira. Imago Editora, (Originalmente publicado em 1900). 
Freud, S. (1976). Análise de uma fobia em um menino de cinco anos (Vol. 10). Rio de Janeiro: Edição Standard Brasileira. Imago Editora. (Originalmente publicado em 1909).

Freud, S. (1976). O estranho (Vol. 17). Rio de Janeiro: Edição Standard Brasileira. Imago Editora. (Originalmente publicado em 1919).

Freud, S. (1976). Além do princípio de prazer (Vol. 18). Rio de Janeiro: Edição Standard Brasileira. Imago Editora. (Originalmente publicado em 1920).

Freud, S. (1976). Inibições, sintomas e ansiedade (Vol. 20). Rio de Janeiro: Edição Standard Brasileira. Imago Editora. (Originalmente publicado em 1926).

Freud, S. (1976). Novas conferências introdutórias sobre psicanálise (Vol. 10). Rio de Janeiro: Edição Standard
Brasileira. Imago Editora. (Originalmente publicado em 1933).

Harari, R. (1997). O seminário, a angústia de Lacan: uma introdução. Buenos Aires: Artes e ofícios editora.

Lacan, J. (1995). O seminário, livro 4: a relação de objeto. Rio de Janeiro: Jorge Zahar editora. (Originalmente publicado em 1956).

Lacan, J. (2005). O seminário, livro 10: a angústia. Rio de Janeiro: Jorge Zahar editora. (Originalmente publicado em 1962).

Recebido em: 7/3/2007

Versão final reapresentada em: 17/5/2007

Aprovado em: 15/6/2007 